\section{No change in emotionality of rats following bulbectomy}

\author{
B. MICHAEL THORNE and LOWELL H. LINDER \\ Mississippi State University, State College, Miss. 39762
}

An attempt to replicate the hyperemotionality syndrome seen in rats following olfactory bulb ablation was unsuccessful, despite the use of a single-blind testing procedure and seven response measures. No difference in postoperative emotionality was found when males and females were compared. Procedural differences were discussed which might account for the failure of the present study to replicate previous results.

It has been known for some time that septal damage and damage to the ventromedial hypothalamus produce increases in emotionality in the rat. A similar finding has been reported for olfactory bulb lesions but has only recently been the focus of experimental attention (Douglas, Isaacson, \& Moss, 1969; Malick, 1970; Seago, Ludvigson, \& Remley, 1970). Malick, in fact, after comparing all three models of hyperemotionality, concluded that "...the O.B. rat manifests more offensive behavior than the other models studied [p. 681]." Despite the strength of this statement, there are conflicting reports concerning the conditions necessary for increased aggression after bulbectomy.

Phillips (1970), for example, did not detect viciousness in his bulbectomized males and assumed that a sex difference accounted for his results, since Douglas et al (1969) had studied females. Further support for a sex difference was provided by Seago et al (1970), who reported viciousness in bulbectomized females. Malick (1970), however, produced at least 97 hyperemotional males.

In addition, there have been some animals in every study of hyperirritability after olfactory bulb damage that have not displayed the syndrome. For example, in the Seago et al (1970) report, 7 of 16 anosmic animals were not vicious. This was true for 5 of 14 Ss in the Douglas et al (1969) study. No explanation was posited in either case for this failure of the model.

The purpose of the present study was twofold. First, an attempt was made to replicate the anosmic syndrome, and second, the sex variable in relation to changes in emotionality was investigated.

\section{SUBJECTS}

The Ss were 24 adult albino rats, 12 males and 12 females. The animals were assigned randomly to the following groups: 4 sham-operated females (SO females); 8 bulbectomized females (OB females); 4 sham-operated males (SO males); 8 bulbectomized males ( $\mathrm{OB}$ males). At the time of surgery, the mean weight of the females was $269 \mathrm{~g}$; mean weight of males was $399 \mathrm{~g}$.

Animals were singly housed and given ad lib food and water, except for a 4-day water-deprivation schedule imposed at the end of the study.

$$
\text { SURGERY }
$$

The animals were anesthetized with sodium pentobarbital $(40 \mathrm{mg} / \mathrm{kg})$ and secured in the headholder from a Baltimore stereotaxic instrument. A section of bone was removed exposing the frontal poles and the olfactory bulbs. Bulb tissue anterior to the frontal poles was removed by subpial males, and OB females. suction after having been separated with a scalpel from olfactory tissue underlying frontal cortex. Sham-operated Ss received the same operative procedure as bulbectomized rats, except that olfactory bulb connections were not severed and the olfactory bulbs were not removed.

At the conclusion of testing, all animals were killed with an overdose of sodium pentobarbital, their skulls removed with mastoid rongeurs, and the entire head allowed to fix in $10 \%$ formalin for 1 week prior to removal of the brain.

\section{APPARATUS}

An open-field box, 30 in. square, was used to measure activity. The floor was marked off into 25 equal squares.

\section{PROCEDURE}

Emotionality was rated once daily for each animal for a total of 14 days distributed as follows: 3 days preoperatively; the first 4 postoperative days; once a week for the second, third, and fourth postoperative weeks; daily for 4 days in which the animals were maintained on a $23 \frac{1 / 2}{-h}$ water-deprivation schedule. The animals were rated on a six-component rating scale described by King (1958). The components were as follows: (1) reaction to a pencil presented visually, (2) reaction to

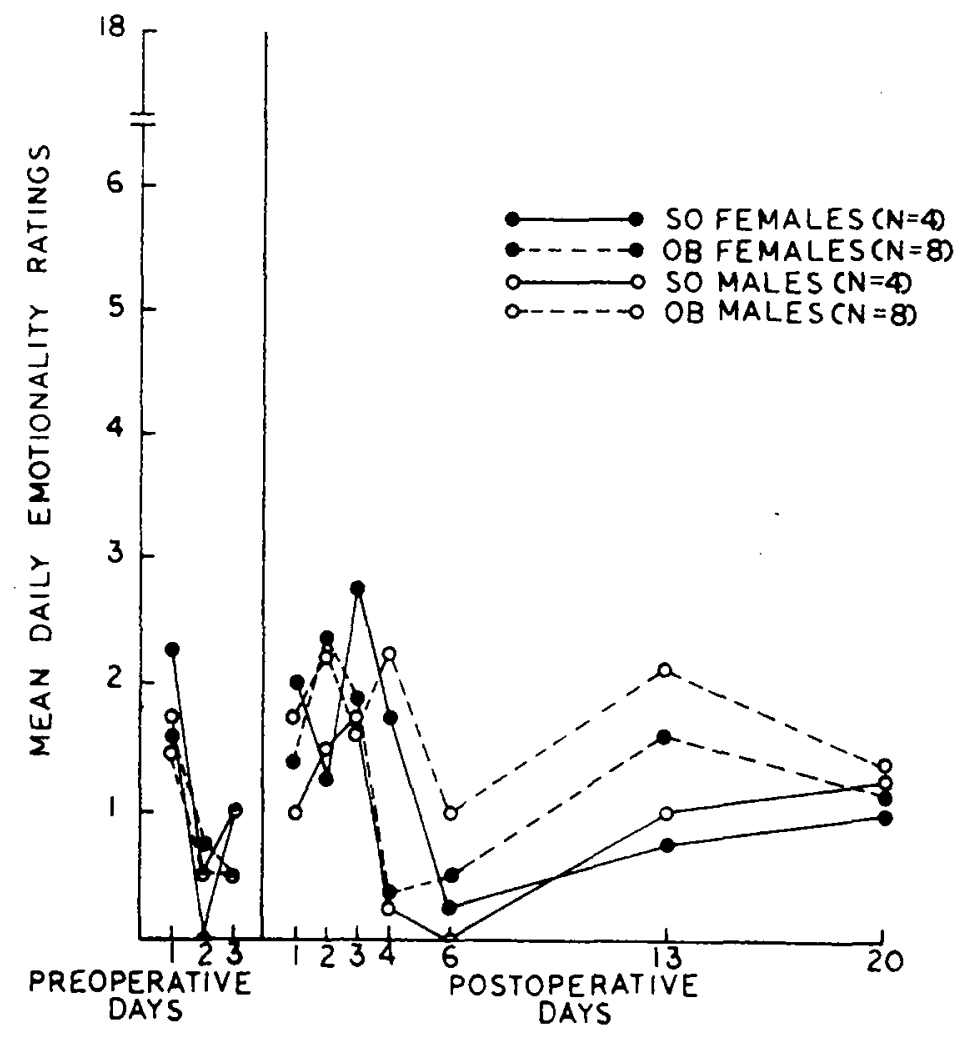

Fig. 1. Mean daily emotionality ratings for SO males, SO females, OB 
pencil tap on the flank, (3) ease of capture from the home cage (4) resistance to handling, (5) amount of vocalization during testing, and (6) amount of urination and defecation in the open-field apparatus. Each component was rated on a 4-point scale (0-3), and each animal was given a daily total based on the sum of the ratings on the six components. In addition, each animal was given a 1-min test of motor activity in the open-field apparatus on each day of testing. During the test, all squares entered or crossed with the hindfeet were counted.

A single-blind procedure was employed to control for $\mathrm{E}$ bias in the postoperative rating of the animals. Thus, the $E$ was unaware of the group to which each $S$ belonged. Reliability checks were performed on 7 different test days through the use of an independent $O$. A correlation coefficient based upon the daily totals for each animal rated by two Es was found to be +0.89. An even higher correlation coefficient was obtained on the independent counting of squares traversed in the 1-min activity test $(r=+0.99)$. The order of testing of the animals was randomized daily so that any given animal would not be consistently influenced by the emotionality of a previously tested S.

\section{RESULTS}

Histology

In every case, there was bilateral removal of at least three-fourths of the olfactory bulb rostral to frontal cortex. In addition, in most animals, there was slight damage to the frontal lobes as well.

\section{Emotionality}

Hyperemotionality was not seen in any animal in the present study. Figure 1 reveals that all animals were initially very docile and remained so after the operations. A nonparametric test comparing the four groups postoperatively confirmed the result indicated by inspection of Fig. 1 $(\mathrm{H}=1.39, \mathrm{p}>.70)$.

The addition of a deprivation regimen did not increase emotionality. The mean daily postoperative score for all animals before deprivation was 1.4

and after was 0.9 .

$$
\text { Activity }
$$

Bulbectomy had no effect upon motor behavior in the open-field test The mean number of squares traversed daily for each group postoperatively was as follows: SO females, 29.6; OB females, 26.0; SO males, 11.1 ; $\mathrm{OB}$ males, 8.7. Females were significantly more active than males throughout testing $(U=8, p<.001)$.

$$
\text { DISCUSSION }
$$

The results of this experiment agree with the incidental observation reported by Phillips (1970), i.e., male rats do not become hyperemotional following olfactory bulb damage. In addition, the results disagree with the findings of Douglas et al (1969), Malick (1970), and Seago et al (1970) concerning hyperemotionality in bulbectomized rats.

There are several differences between this study and previous ones which might account for the divergent results. First of all, viciousness following bulbectomy might be characteristic of a particular strain of rats. In line with this possibility, both Douglas et al (1969) and Malick (1970) used hooded rats in their studies. However, Phillips (1970) also used hooded rats and did not produce viciousness, while Seago et al (1970) found viciousness in Sprague-Dawley albino rats. Animals used in the present study were albinos of mixed lineage.

Secondly, a deprivation schedule was initiated at the end of the present study in order to test the possibility that the hyperirritability seen in the Seago et al (1970) study resulted from deprivation associated with a learning task. The negative results obtained, however, diminish this possibility.

A third difference stems from the disparate testing procedures employed. In the previous studies reporting emotionality, only one or, at most, two measures were used. Malick (1970), for example, used as a criterion of viciousness aggressive responses to a stick and a glove by animals who were restrained. In the present study, animals were not restrained during testing, and not a single rat ever made an aggressive or defensive response to the sight of a pencil. Additionally, none of the previous reports employed a single-blind procedure.

A fourth possibility concerns the extent of damage to olfactory bulb tissue in this and in other studies. Because of the difficulties involved in removing rat brains without damaging olfactory bulb material, previous reports have provided only very brief descriptions of the damage produced. The operative procedures have been the same in all cases, i.e., an attempt was made to remove all olfactory bulb substance rostral to the frontal lobes. Douglas et al (1969) provided probably the most complete description of damage produced, and since no damage to the frontal lobes was found, it is doubtful that more extensive lesions could have been produced in their study than in the present experiment. Animals in the present study with frontal lobe damage were neither more nor less aggressive than those without such damage.

Douglas et al (1969) proposed a psychological explanation for the O.B. syndrome involving loss of vital sensory information and the resulting disorientation. In a learning study in this laboratory, male rats have been subjected to both enucleation and bulbectomy without having become vicious.

REFERENCES

DOUGLAS, R. J., ISAACSON, R. L.. \& MOSS, R. L. Olfactory lesions, emotionality and activity. Physiology \&c Behavior, 1969, 4, 379-381.

KING, F. A. Effects of septal and amygdaloid lesions on emotional behavior and conditioned avoidance responses in the rat. Journal of Nervous \& Mental Disease, 1958, 126, 57-63.

MALICK, J. B. A behavioral comparison of three lesion-induced models of aggression in the rat. Physiology \& Behavior, 1970 . $5,679-681$.

PHILLIPS, D. S. Effects of olfactory bulb ablation on visual discrimination. Physiology \& Behavior, 1970, 5, 13-15. SEAGO, J. D.. LUDVIGSON, H. W.. \& REMLEY, N. R. Effects of anosmia on apparent double altemation in the rat. Journal of Comparative \& Physiological Psychology, 1970, 71, 435-442. 